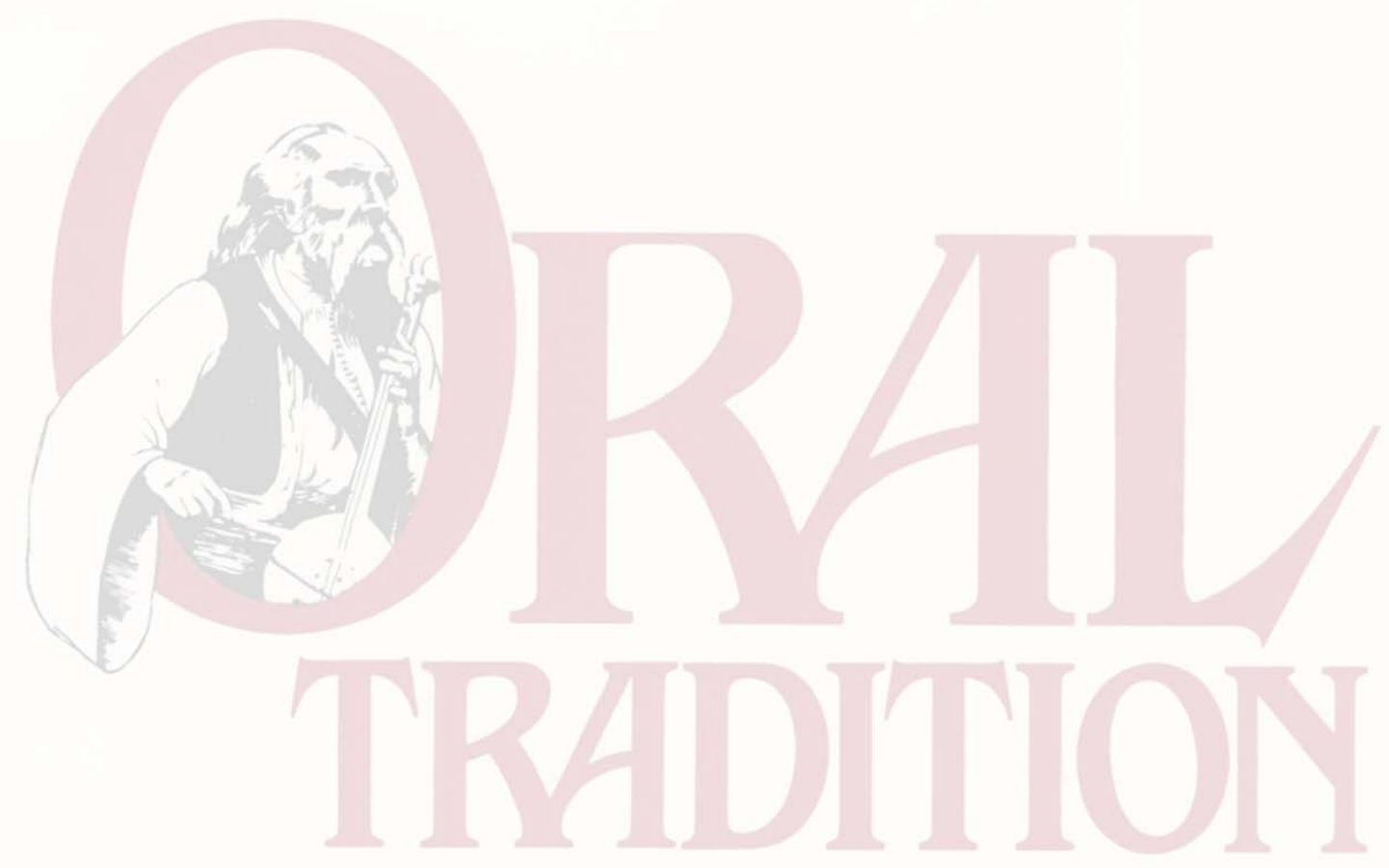

This article belongs to a special issue of Oral Tradition published in honor of John Miles Foley's 65 ${ }^{\text {th }}$ birthday and 2011 retirement. The surprise Festschrift, guest-edited by Lori and Scott Garner entirely without his knowledge, celebrates John's tremendous impact on studies in oral tradition through a series of essays contributed by his students from the University of MissouriColumbia (1979-present) and from NEH Summer Seminars that he has directed (1987-1996).

http://journal.oraltradition.org/issues/26ii 
This page is intentionally left blank. 
Oral Tradition, 26/2 (2011): 523-534

\title{
Vernacular Phrasal Display: Towards the Definition of a Form
}

\author{
Adam Brooke Davis
}

\section{In Principio...}

Mabel was the daughter of a Baptist pastor; she played the organ in her father's church. It would not have occurred to her to appear on the sidewalk without her hat and white gloves. But those hands could also slaughter a hog, or inspire an errant child to reform, and the voice that could so soulfully croon "Just As I Am" had been heard to criticize the mealy-mouthed sort that "wouldn't say shit if he found himself with a mouthful." It was understood that when Mabel said, "Jump!" the only conceivable response was "how high, ma'am?!" Mean enough to hunt bear with a switch if it came to that. . . Mabel was my personal introduction to a traditional, if for the most part unrecognized, genre of verbal performance.

\section{Crowdsourcing a Corpus}

For many years, at the Missouri Folklore Society website we've maintained an archive titled "Colorful Language of the Rural Midwest, with special emphasis on Missouri and Missourians" (http://missourifolkloresociety.truman.edu/expressions.html). The header is descriptive, if inelegant. The collection began with my own list, accumulated over a number of years from my own family's oral history, with the nucleus of the collection consisting of speechitems collected from my famously profane grandmother. Although she lived nine-tenths of her life in Missouri, her native speech was primarily that of Western Kentucky, thus exemplifying the much-travelled nature that we will see to be common for such forms. Even within my own family, these speech-items were understood as a definable corpus that was meaningfully referred to as "grammaw's sayings."

In the years that followed, the collection's rapid growth proved both gratifying - we were clearly on to something - and frustrating, specifically for the professional folklorist. Classically, the scholar pursues a subject according to the pattern collect-classify-interpret (to which we might then also add assimilate to existing theory, and propose modifications to theory). But in the case of this collection, such discrete parts of the folklorist's process became quickly intermingled, thus mirroring the characteristics inherent in the medium in which we chose to archive the collection. The World Wide Web, as is now generally recognized, is not merely an extension of print culture, capable of faster turnarounds on publication and revision, but a 
transformation of it. The abilities to search and collaborate have had special significance for folklorists and linguists doing corpus studies, most particularly when that corpus is maintained and developed on the web itself. ${ }^{1}$

Evidently, in our case what was happening with some regularity was that an individual would begin by searching via Google for a recently recalled phrase that had been heard once long ago. For example, if one searched for the phrase "slick as a jar full of eels," our site was one of the top results that would be retrieved. ${ }^{2}$ Following the hyperlink, the user would find an archive of hundreds of entries provided in no particular order. And at least in some instances, there would come a moment of illumination. Reviewing our collection, the visitor would find duplicates of, or variations on, many other remembered phrases as well. Such an encounter with familiar but distinctive constructions would then act as a sort of key to a memory vault. The Anglo-Saxons called it a wordhoard, a treasure-chest of verbal riches. ${ }^{3}$ Commonly, visitors would even augment their visit by communicating further, often through messages with a typical form: "Your site made me laugh so hard . . . I remember all these old things. . ." And there would then follow a list, often long, as the single key opened another box within the first. I would sometimes exchange emails with these informants, hoping to get basic ethnographic information on the sample in question, for example, the alleged originator's native place and birth year, gender, and level of education. ${ }^{4}$ Without exception, correspondents focused on the vividness of the imagery in these expressions, with special appreciation for the humor involved, though they frequently felt the need to apologize for salty content. This reaction is hardly

1 The most obvious of a great many relevant instances one could mention is Foley's Pathways Project (Foley 2011-). As I was completing my dissertation under his direction in 1990, very few academics (fewer still in the arts and humanities) were aware of the Internet. At that early period, John was among the first to grasp the capacity of this new technology to restructure our communicative life as radically as the printing press had done. And he was utterly alone in intuiting its affinities to oral tradition, what The Pathways Project's homepage now refers to as "the fundamental similarities and correspondences between humankind's oldest and newest thoughttechnologies." He was already speaking, at that early date, of the difference between canon and pathway, and his insistence upon verbal art as behavior that is situated within complex contexts, including other behaviors, present to the speaker and related to prior performances, provides the foundation for the present inquiry.

2 Specifically, the user is directed to the "Ol' Shep" section of the site, the title of which refers to the shaggy-dog story behind the family catchphrase with which the site began. That was a long time back ("since Hector was a pup;" "since Pat was in the army"), but it seems somehow fitting that we should now leave it as it is.

${ }^{3}$ Admittedly, the genre at hand lacks the gravitas of the sustained discourse on which oral tradition theory was for the most part built. However, I am drawing on the same conception of a pre-existing set of signifiers that remain latent in memory until called forth by the performer's recognition of a suitable situation for deployment. Once a given figure is deployed, it becomes itself part of the communicative matrix and places constraints on what may or even must come next. See further the first two chapters of Foley 1995, particularly their characterization of "performance as the enabling event and tradition as the enabling referent" (28), a hieros gamos solemnized within the performance arena "where words are invested with their special power" (47).

${ }^{4}$ I could seldom get informants to provide such data, as is easily done in face-to-face interviews or when sampling consists of having informants fill out forms. However, attempts to gather material in those ways have proven unsuccessful, probably because of the triggering mechanisms already discussed as underlying the recollection process. Informants seem to self-select by what they choose to search for on the web. Those who find our archive in that way, and share their gems, usually seem to have little desire to tarry. 
surprising, as flirting about the edges of acceptability seems - as we shall soon see- to be so common a feature of the form that it may even be functionally definitive. ${ }^{5}$

\section{Genre Intuited, Not Defined}

I have not yet described what is meant by "the form" or "these expressions." There are numerous terms currently in circulation for the phenomenon we are here discussing - a sure sign to the scholar that there's a there there- but a universally accepted name for that phenomenon has not yet been coined. As a starting point, we can note that the concept of a "folk simile" (or "proverbial comparison") has previously sometimes been categorized as a genre of verbal folklore and a variety of "folksay" (described by Brunvand as "the short, verbal, non-narrative forms of folklore" [1976:57]). ${ }^{6}$ In English, according to the present understanding, folk similes typically use "like" or "as," are vivid in imagery, and are in relatively broad (though perhaps geographically or sociologically restricted) circulation. They may contain humorous exaggeration and are often obscene. The form can be described to some degree in terms of grammatical structure, but also by rhetorical patterns and - though not to date in print — by social function. Typical examples collected by Max Hunter include "pretty as a speckled pup" and "ugly as a mud fence."

Other names in use for this type of speech-item reflect the particular features that investigators have wished to foreground in their individual studies. Where (as is often the case) the vehicle of the comparison (implied or explicit) is lewd, rude, or otherwise objectionable by conventional conversational standards, we find the term "Vulgar Comparative Metaphor," with "vulgar" being used with both its deprecatory sense and with its meaning of "common" or "popular." Alternatively, a focus on inventive overstatement as a rhetorical device gives rise to the term "proverbial exaggerations" (Green 1997:662), with the expressions often treated under the heading of "proverb" since they may imply what is essentially a proverbial insight and lack known authors. Accordingly, they may unsurprisingly later be ascribed to a given individual who has developed a reputation for facility with such expressions, frequently a family elder, for

${ }^{5}$ For instance, this is certainly the case with limericks.

${ }^{6}$ Brunvand (1976:57) credits the coinage to Benjamin Botkin. The scholarly prominence of Archer Taylor (1954, 1958, 1962) did much to establish the designator "proverbial comparison," though he also used "folk simile." In the most recent of the very few systematic studies of the genre, Revak (2005) discusses terminology to date; her bibliography lists a number of notable collections.

${ }^{7}$ Such examples are mentioned in his numerous obituaries (for example, in The Bangor Daily News, 11 November, 1999, p. B7 col. A.

8 This term is used, for example, as the title of a website devoted to these types of speech-items: http:// www.yaelf.com/vcmf.shtml.

${ }^{9}$ Similarly, Taylor (1962:201) connects the genre to the Wellerism (which he has the distinction of naming) and notes the "often obscene humor and ... lack of a moral or didactic turn. .. " (206). 
example, and so become known as "Grandma's sayings." 10 The expressions are also somewhat inaccurately but nonetheless quite insistently identified with rural or archaic folk speech, as for example in the title of Randolph's Down in the Holler: A Gallery of Ozark Folk Speech (1979). As Hendricks points out (1960:245), expressions that are felt by their users to be regional often turn out to be of wide distribution and historically attested. Moreover, comparisons where the vehicle is connected to a distinctly urban lifeworld are much in evidence, as in "meaner than a junkyard dog," a phrase that may or may not have been original to Jim Croce but that is authentically "folk" in form and feel.

In our own collecting, we hear from cyber-informants that these were "Uncle Pat's sayings," "my college roommate's expressions" "my mother's way of talking," or "Jim-Bobisms." Consistently, texts are ascribed to a figure of legendary eloquence- a parochial and hyperspecialized Homer. ${ }^{11}$ Additionally, there was a clear sense that these expressions belonged to a bygone era and were strongly linked to rural lifeways. ${ }^{12}$ Informants and collectors alike showed nostalgic awareness of cultural loss, implicit in the fact that the concrete details referenced in these metaphors and similes were quite often those of a lifeworld perceived as lapsed. Nearly always, those involved had a strong conviction that these expressions were distinctive to a particular area - a certainty that was nearly always demonstrably misplaced, as I would regularly receive nearly if not precisely duplicate submissions from places as widely separated as the Carolinas, Tennessee, Texas, and even the Canadian Maritimes or Australia. ${ }^{13}$

Thus far, my fieldwork in cyberspace told me several things about these sayings:

- they appeal to people on a variety of levels

- they evoke nostalgia

10 An anonymous informant born in Joplin, Missouri, in 1930 reported (conversation, Neosho, Missouri, November 2010) that the genre was known in his youth as "eddered sayings." He speculated that the word was the equivalent of "uttered" but was unable to explain the precise meaning.

11 Revak (2005:311, n. 1) notes that Boshears collected over a thousand such items from a single East Tennessee informant. It is certainly possible to gain a local reputation for eloquence and mastery of a genre, with such a person being credited as the originator of material in the common wordhoard. For example, a web-search for the phrase "nervous as a whore in church" reveals its presence in collections dedicated to-charmingly - "Foleyisms" (http://www.thataintnormal.com/?page id=48) as well as to those surrounding other specific individuals.

${ }^{12}$ Again, the phrase "nervous as a whore in church" appears in web collections designated as "southern sayings" (http://www.thecoffeeplace.com/jokes/aaaaabsc.html), "hillbilly/redneck sayings" (http://nwoutdoors.net/ index.php?action=printpage; topic=685.0), "Texas sayings" (http://www.texasmonthly.com/1000-01-01/ webextra35.php), and "old timey sayings" (http://clinchredroom.proboards.com/index.cgi? board $=$ general\&action $=$ print\&thread $=563$ ), though northern cities today are not notoriously short on either prostitutes or houses of worship.

13 The most widely distributed example to date, claimed to be distinctive to each of these locales, is "nervous as a long-tailed cat in a room full of rocking chairs." Very early on I went through the exercise of sticking pins in a large map of the United States, and pursued it far enough to become certain that there was no point. I had thought I might see the expressions correlating to established settlement patterns, assuming that the collected items indeed proved sufficiently archaic. I still think that, working digitally (so as to be able to cut the data out in different dimensions, overlaying time-strata with location) and with a sufficiently massive database (many, many thousands of data points would be necessary), I might be able to replicate and document what is already thoroughly wellknown about European migration in the United States. 
- humor is regarded as a defining feature

- taboo regularly appears

- they evoke and activate passive memories; deploying a particular item can unlock and access archives of similar material

- they are believed to be linked to notable individuals

- a facility with these forms can confer a certain notability on a skilled practitioner

- they are believed to be place-linked

- these speech forms are widely distributed

\section{Features and Variation: Structure, Content, Meaning}

Meanwhile, as items accumulated, further patterns emerged. For instance, it became evident that sound-patterning and other rhetorical devices work to enhance the memorability of the speech-items and elevate their speaker's status: ${ }^{14}$

alliteration: useless as a sidesaddle on a sow; mean as Moody's goose

rhyme: dumb as a box of rocks; in like Flynn

assonance: cool as a blue moose; drunk as Hogan's goat ${ }^{15}$

It is of course possible for an item to lose some perceived rhetorical vividness through overuse and therefore to become a mere cliché ("pretty as a picture," "dead as a doornail").Very much as with the proverb, the expression is relatively fixed, or at least of constrained variability. Thus, tasks that are both overwhelming in scope and tedious in their demands for detailed attention often get described through the phrase "needle in a haystack," but not "* pin in a pile of straw" (though that would have the virtue of alliteration). ${ }^{16}$ Nor do we ever hear of a "*needle in a hay-bale."

Additionally, the form is not defined by strict syntactic rules, though there are common grammatical patterns. Much effort has gone into the attempt to define a formal framework that would capture the range of items in the collections, but no satisfactory conclusion has yet been

\footnotetext{
${ }^{14}$ Unless attributed to another source, all examples are taken from the Missouri Folklore Society archive.
}

${ }^{15}$ Of course, much time has been lost trying to identify Moody, Hogan of the unfortunate goat, and other such named individuals. Cecil Adams of The Straight Dope, however, acting as folk informant, assures readers that Flynn was none other than Errol, and that "in" meant precisely what they are likely to think it meant, although Cecil was certain his mother didn't know that when she borrowed the phrase. These proper names may be preserved out of sheer inertia, but I suspect they have a deictic function, creating a fictive familiarity by miming the rich, shared, implicit knowledge typical of high-context communication among intimates. If this is so, it is related to the affective qualities of familiarity and intimacy that are regularly linked to the genre. unacceptable.

${ }^{16}$ I use the standard linguistic convention of marking with an asterisk any form unattested or thought to be 
reached. Nevertheless, as Orr (1976:176-78) $)^{17}$ has shown, four familiar formal structures predominate:

1) similes using the conjunction "as":

Noisy as a cow in a rail-pile

Ugly as a blind cobbler's thumb

2) similes using the conjunction "like":

like hogs eating their young [said of an unpleasant noise]

I'm gonna beat you like a rented mule

3) formulations in the comparative degree using "than":

busier'n a cat coverin' shit ${ }^{18}$

4) proverbial exaggerations using the words "so . . that ...," "too . . to . ..," and ". . enough

to ...":

So drunk [that] he can't find his whatsis with both hands and a roadmap.

Too dumb to pour piss out of a boot with the instructions printed on the heel.

He's got money enough to burn a wet mule.

Tall enough to stand flatfooted and screw a flyin' buzzard.

Another feature of the genre that has escaped notice in print is that these expressions are in a strict sense traditional, that is, one experiences them as part of a received repertoire. My own intuition, based simply on my aesthetic experience of the genre as performance, is that hearers judge the individual expression to be authentic to the degree it seems pre-configured to the genre even when it is heard for the first time. However, a given phrase is also an individual possession insofar as the audience appreciates its creativity and vividness. The possessor's role is to be an impressive performer and custodian of the verbal inheritance. The speaker exploits the rhetorical moment, recognizing the situation and reaching without hesitation for the right illustrative phrase to provide it with an emotional frame. For example, we get multiple attestations of the following pair:

Crazy as a pet raccoon

Crazy as a shithouse rat

And while we will find "lazy" and "mean" associated with the pet raccoon, as well as synonyms for mental disease ("goofy," "nutty"), the shithouse rat seems to be tied pretty firmly to the

17 Orr's appendix (pp. 184-208, consisting of her 1975 collection) is organized on this structural grid; Revak (2005:306-09) offers a nine-part structural division.

18 The full form ends "on a linoleum floor" or "on a waxed floor;" the occasion is served as well by a multiform concerning one-armed paperhangers or one-legged men in ass-kicking contests. Content is not tied to structure; "noisy as a cow in a rail-pile" is attested in this comparative form as well through the "noisier than a cow in a rail-pile." 
specific word "crazy." Pursuing the complexities of variation from the direction of the core adjective, when "crazy" is linked to "fox," it's never "crazy as" but only "crazy like." The phrase also seems to have an urban, perhaps Yiddish matrix, and the main syntactic constraint is also a semantic constraint and a genuine point of beast lore: a fox is not crazy, but a certain kind of cunning may be mistaken for mental deficiency, and the misapprehension is prevented or corrected through this essentially proverbial reminder. Moreover, our initial pair is interesting here in that a trope can be inferred; in both cases, the vehicle gets an attributive adjective that specifies it as occupying human space where it does not ordinarily belong, a contrast of wildness with domesticity. It's the sort of gesture by which humanity has always both taught and maintained its norms.

Then we have cases of simple and clear expansion. Some instances seem to be simple ad libitum insertions:

Ugly as sin

Ugly as home-made sin

There is of course an inventive gesture here; the receiver is handed an active task, in that one is provoked to wonder how home-made sin differs from other kinds, or to backform the contrastive case, "storebought sin" (rehearsing that culturally important dyad may be a subordinate function of the phrase). ${ }^{19}$ The feature suggests that the speechform is in some aspects aligned with the traditional riddle, which, while often humorous, is ethnographically more closely related to proverbs and other wisdom literature than to jokes and is equally likely to invoke taboo in order to provoke deep, if prelinguistic, reflection (Davis 1992). Such expansions also act as an indicator of the genre's close ties with performance, as the elaborations often seem geared toward drawing greater attention to themselves through added absurdity. ${ }^{20}$

Ugly as a mud fence

Ugly as a mud fence stuck with tadpoles

Heightened absurdity through expansion also forces an audience to imagine the aesthetic that would involve tadpoles as an ornament or improvement upon something already bizarre and irredeemably ugly. People in a lifeworld where one builds one's own fences, and quite laboriously, will be particularly amused by the idea of someone going to herculean efforts to construct such a hideous thing. Additionally, such expansions sometimes become so spectacular

19 An anonymous elderly informant living in Kimmswick, Missouri, claimed that the original is "ugly as homemade soap" (conversation, Neosho, Missouri, November 2010); such an origin seems on the surface entirely credible, as even within my own family's living memory, store-bought soap was taken as an index of sophistication, urban orientation, and prosperity.

20 Bizarre, surreal imagery features regularly, as does "the primitive humor of cruelty" (G. C. Bellamy’s phrase [1950:122-23] for a feature recognized in Twain, though the author does not describe it as a characteristic adapted from folk narrative): "We ain't had this much excitement since the hogs et junior;" "That's when the lightning hit the merry-go-round." 
with regard to absurd imagery, alliterative excess, or obscene language that one cannot help but conclude that an element of intended theatricality is involved. As Orr has noted (1976:179):

Through phrase elaboration and phrase-combination, variant forms of each comparison are created. Phrase-elaboration enables a succinct version of a comparison such as "as hot as a fox" to be lengthened to "as hot as a fox in a forest fire" and "as hot as a fresh-fucked fox."

One notes, however, a certain decorum. "*Hot as a fresh-fucked fox in a forest fire" is unattested. Presumably there are limits.

\section{This Too Shall Pass: A Case Study}

I would now like to proceed by examining a complex of expressions that are clearly generated by a single underlying template but linked to one another through a cluster of images that show evidence of being swapped out, one for another, on a modular principle and in response to constraints encountered in performance. If we look at pairs of related traditional comparisons in terms of traditional rhetorical structure, where a thing (tenor) is compared to something else (vehicle), ${ }^{21}$ we can identify pairs where either one seems to be substitutable; first we see a change in at least part of the vehicle:

Shivering like a dog shitting razorblades

Shivering like a dog passing peach pits

On the other hand, substitution of the tenor is also possible, with an angry preacher reportedly being described as

Stuttering like a dog passing peach pits

This particular example can serve to illustrate the structure of a good many of these expressions, which we can schematize thus:

element 1 like/as element 2

element 1 consists of shaking (or quaking, stuttering, shivering, etc.)

element 2 is broken down into several subunits, any of which can be substituted or expanded, though the samples suggest limits and restrictions on such variation:

element 2a: dog (poodle, beagle)

element 2b: passing (crapping, shitting)

21 The famous formulation is that of Richards (1936:96); in terms of metaphor mapping as treated by cognitive linguistics, the corresponding terms are target and source. 
element 2c: peach pits (razor blades, thumbtacks, kidney stones)

There is a stability underlying element 2 that can be expressed as:

$$
\operatorname{dog}+\text { excrete }+ \text { sharp object }
$$

Numerically, in our collected variants of this example there is a strong preference for filling the three slots with "dog" for subject (2a), "pass" for verb (2b), and "peach pit" for direct object (2c). It would of course be desirable to follow a single speaker or speech-community in order to determine exactly how individuals or larger communities vary their substitution patterns in accordance with the performance arena. For instance, does a performer who regularly chooses "pass" as the verbal element sometimes downshift in register to "crap" or "shit," with some situations and speech environments favoring dysphemism? Unfortunately, these expressions are by their very nature situation-bound, and to maintain unremitting surveillance on reputable performers until circumstances could call forth enough demonstrations to build a statistically meaningful sample is impossible.

The skill within this speechform, then, is in identifying the substitution slots available for adapting the image to the particularities of the occasion, and our above schema can be made even more complex by noting that further substitution possibilities exist for the first element of the expression. Setting aside what are more or less synonyms for "shaking" ("quaking," "trembling," "wobbling"), we still find significant variation in this first slot:

Panting like a dog passing peach pits

Crying like a dog passing kidney stones

Whining like a dog passing thumbtacks

This first element directs hearers' attention to the occasion of deployment for the expression, and the skillful user of these phrases must quickly recognize the situation, select an image to capture it, and choose a suitable term. Present participles seem to be strongly favored in this slot. Of course, the decision must be made without hesitation, second-thoughts, or disfluencies. At this point, it is probable that further decisions about alliteration, assonance, or rhyme are made, and the second element is thus limited in its variability accordingly.

\section{Conclusion}

A future task exists that both appeals and appalls: the creation of a properly organized corpus, one in which items can be coded so as to be organized by rhetorical structure, conversational topos, lexical choices, sphere of reference (urban, rural, animal lore, railroad culture, automobile culture, horse culture, and so on), ${ }^{22}$ or other dimensions. A digital collection

22 Taylor $(1962: 66-67,188)$ long ago made a similar proposal concerning proverbs more generally. Fifty years later, the opportunity is available. 
also allows ethnographic detail on informants to be encoded, though often that information is sparse. Of these prospects, an index by rhetorical occasion seems the most useful. Within this tradition, the goal is not merely to hoard pretty phrases or even suitably flexible stock responses. Instead, a collection of these items functions as an attitudinal armory, a supply of rhetorical devices that gives the bearer definitional initiative and privilege within specific contexts, the power to set the tone and understanding of a range of recurring situations. To own these items and be adept in their use quite rightly brings repute, and this dimension of the tradition is accessible only if we move beyond formal considerations and unfounded claims of provenance to performance and function.

With such concerns in mind, then, I close by proposing the term vernacular phrasal display to encompass these moderately fixed expressions that cannot be completely assimilated into a single, specific grammatical or rhetorical structure. Further work is of course necessary, perhaps beginning by investigating practices in other languages, where similar sociolinguistic challenges provoke similar responses, though the particularities of a given linguistic tradition will be at least as interesting as the points of convergence. I would also encourage further inquiry into whether the use of a particular archive of imagery sometimes has group-definition functions, effectively defining its circle of speakers and listeners as the type of people who recognize that sort of imagery. For the outward form of vernacular phrasal displays (often overtly metaphorical) suggests an intention to illuminate the subject at hand, yet socially (in actual presentation) these phrases - as integral parts of a performance-genre used primarily to secure the practitioner's reputation - in fact serve to spotlight the individual speaker.

Truman State University

\section{References}

Adams 1996

Bellamy 1950

Boshears 1954

Brunvand 1976
Cecil Adams. “The Straight Dope: Does ‘in like Flynn’ refer to Errol Flynn's success with women?" September 6, 1996. http://www.straightdope.com/ columns/read/1127/does-in-like-flynn-refer-to-errol-flynns-success-withwomen/

Gladys Carmen Bellamy. Mark Twain as a Literary Artist. Norman: University of Oklahoma Press.

F. Boshears. "Proverbial Comparisons from an East Tennessee County." Tennessee Folklore Society Bulletin, 20:27-41.

Jan Harold Brunvand. Folklore: A Study and Research Guide. New York: St. Martin's Press. 
Davis 1992

Davis 2010

Foley 1995

Foley 2011-

Green 1997

Hendricks 1960

Missouri Folklore Society

Orr 1976

Randolph 1979

Revak 2005

Richards 1936

Taylor 1954

Taylor 1958

Taylor 1962
Adam B. Davis. "Agon and Gnomon: Forms and Functions of the Anglo-Saxon Riddles." In De Gustibus: Essays for Alain Renoir. Ed. by John Miles Foley. New York: Garland. pp. 110-50. "Slicker'n Deerguts on a Doorknob." Truman State University Folklore Colloquium. Kirksville, Missouri. 23 November.

John Miles Foley. The Singer of Tales in Performance. Bloomington: Indiana University Press. The Pathways Project. http://pathwaysproject.org/

Thomas A. Green. Folklore: An Encyclopedia of Beliefs, Customs, Tales, Music, and Art. 2nd ed. Santa Barbara, CA: ABC-CLIO.

G. D. Hendricks. "Texas Folk Similes.” Western Folklore, 19:245-62.

Missouri Folklore Society. Colorful Language of the Rural Midwest, with special emphasis on Missouri and Missourians. http://missourifolklore society.truman.edu/expressions.html

Cathy M. Orr. "Folk Comparisons from Colorado." Western Folklore, $35: 175-208$

Vance Randolph. Down in the Holler: A Gallery of Ozark Folk Speech. Norman: University of Oklahoma Press. Rpt. of 1953 edition.

Kelly Revak. "As Easy as Collecting Feathers in a Hurricane: A Re-Definition of the Folk Simile." Proverbium, 22:303-14.

I. A. Richards. Philosophy of Rhetoric. Oxford: Oxford University Press.

Archer Taylor. Proverbial Comparisons and Similes from California. Folklore Studies, 3. Berkeley: University of California Press.

"More Proverbial Comparisons from California." Western Folklore, $17: 12-20$.

The Proverb and an Index to the Proverb. Hatboro, PA: Folklore Associates. 
This page is intentionally left blank. 